\title{
The potential of information technology for nurses in primary care: a review of issues and trends
}

Laurence Alpay Institute of Educational Technology, The Open University, Gill Needham OU Library, The Open University and Peter Murray School of Health and Social Welfare, The Open University, Milton Keynes, UK

\begin{abstract}
This article presents a review of current issues and trends in the use of information technology (IT) by nurses in primary care. Its aim is to raise awareness of the particular problems faced by nurses, and so it is not aimed at the IT expert but at the primary care nurse, researcher or educator who seeks a wider perspective on the issues involved. It is not the purpose of this paper to offer specific solutions to the problems; these will be discussed in further publications. The first section highlights recent policy changes in the area of information technology that are already affecting nurses in primary care. The second section addresses some of the barriers to progress in this area, which should be taken into account if the Government's vision of an IT-rich health service is to be achieved. To draw attention to the fact that nurses in other countries face similar issues to those in the UK, we include a wide selection of international as well as national literature. Finally, the third section suggests how these barriers might be overcome, and identifies emerging trends.
\end{abstract}

Key words: information technology; nursing; nursing education; primary care

\section{Background: information technology in health care and primary care}

The launch of the recent information strategy for the health services, Information for Health (Department of Health, 1998a), seems to promise a bright new dawn for the use of information technology (IT) within health care in the UK.

Coupled with the Government's overall vision for the future development of the NHS as set out in the White Paper (Department of Health, 1997) and other subsequent documents dealing with the delivery of quality services, such as A First Class Service (Department of Health, 1998b), there certainly seems to be top-level commitment to widespread change in the nature of health services and the forms of delivery. However, there is still an important contrast between the current reality of

Address for correspondence: Dr Laurence Alpay, Prinses Annalaan 488, 2263XX Leidschendam, The Netherlands.

(C)Arnold 2000 nurses' computer use in primary care, and the future vision as made explicit within this recent information strategy. If current reality is to be transformed into the future vision, a serious skills gap will need to be urgently addressed.

The use of IT is seen to be integral to the development and delivery of health services, with Information for Health setting out a 7-year timetable for the development of widespread electronic information storage and exchange across all parts of the health service. Such an implementation has profound implications for the way in which all nurses and other health professionals work, and has equally vast implications for their education and training needs, to enable them to use the new technologies that the strategy promises.

The emphasis on the need for clinical benefit from computer systems has been widely welcomed within the health professions, and is generally seen as a much-needed contrast to the previous financeand management-driven Information Management and Technology (IM\&T) strategy. However, many

1463-4236(2000)PC003XX 
of the factors which will determine the success or otherwise of these developments as we move into the twenty-first century are human factors. Furthermore, there is increasingly a shift from focusing on the intricacies of the technology to considering how best to manage information using it. These factors, rather than any detail of the technological issues, will be explored in this paper.

If we are to believe what has been said and written about the development of computer systems within the health service, primary care would already seem to be well served by the technology and well placed to take advantage of the benefits to patient and client care promised by the new direction and focus. There has been substantial financial investment in computer systems for general practices in recent years, and it is now estimated that well in excess of $90 \%$ of practices in England are computerized. The Government now envisages all practices being computerized by the year 2000. However, there is concern that although such systems may be in place, they have been and will continue to be - used primarily by general practitioners (GPs) (e.g., for repeat prescribing and for financial and administrative purposes), and have generally not been used by or provided any direct benefit to nurses.

\section{Obstacles to access to and use of information technology}

Although in the past few years most general practices in the UK have invested in computer technologies (Brown, 1998), a number of problems associated with computerization in primary care still remain. This section highlights some of the difficulties encountered in making information technology work for nurses in primary care, namely attitudes to computerization, changes in work practices, and education and training needs in IT.

\section{Attitudes towards computer technology}

For computerization in health care to be successful, the attitudes and concerns of health-care professionals, and particularly of nurses, need to be considered. Recent literature has reported on nurses' mixed and ambiguous attitudes towards the use of computers and information technology (e.g., Scarpa et al., 1992; Lacey, 1993). Such negative attitudes towards computer technology affect both the use of and access to IT. Negative attitudes have developed when, for example, nurses have had unsuccessful experiences with computer systems. In conjunction with the nurses' own past experiences of computers, their perception of what computer technology can or cannot provide is very important. There is still a gap between the nature of nursing as provision of care and nurses' understanding of the benefits of IT to support patient care (Simpson and Kenrick, 1997). Furthermore, there is also the perception that computers take away nurses' responsibilities. For example, some nurses view computers as a threat that challenges their traditional codes of ethics and confidentiality (Miller and Jeffcote, 1997).

Another factor which influences nurses' attitudes towards computerization concerns cultural differences. For example, Marin et al. (1998) have investigated nurses' requirements for information technology in the USA and in Brazil. Nurses in the USA were found to be more comfortable with computers than nurses in Brazil, and in each country they had a different view of the role of computers within their work practices. For example, nurses in Brazil tended to agree that computers should be mostly used in the administrative nursing area, whereas nurses in the USA believed that computers could help in other nursing areas as well. Mixed feelings about how IT can support nurses in different countries were also reported by Simpson and Kenrick (1997). They compared attitudes towards computerization in the UK with a similar study in the USA. Although their results show that the UK situation was not too dissimilar to that in the USA, they found that other underlying factors were affecting attitudes towards computer technology, including age, gender, and experience as a nurse. For example, it was found that older nurses who had not been trained in IT during their nursing studies were more likely to display negative attitudes towards computer technology. With regard to the gender factor, Simpson et al. (1998) reported that in general practices, it was more likely that male partners than female partners had responsibility for computer development.

Closely related to negative and ambiguous attitudes, anxiety about and resistance to computers contribute to the difficulties in accepting and using computer technologies. Negron (1995) reports on the impact of computer anxiety on nurses using IT. 
Resistance to computer technologies includes both resistance to learning and lack of information. Another type of resistance is that to change generally, including using computers. These are serious problems that need to be addressed. Otherwise, they will continue to hinder progress in the use of IT to support and deliver patient care.

\section{Changes in work practices}

The mode of health-care delivery is undergoing major changes. Nowadays the style of patient care delivery is moving towards integrated care. Primary care centres are organized around multiprofessional teams, and within the primary care team the role of the nurse in the UK is changing rapidly. Nurses in the UK now play an active role in disease management and health promotion, while primary care groups (PCG) can give nurses a clear role as part of PCG boards involved in commissioning health services for their local population.

Changes in work practices may be strongly influenced by technological changes, and technological innovations may drive the change to progress. Many of the studies (e.g., Hall, 1996; Fogarty, 1997; Shepherd, 1999) investigating current and projected use of information technology in general practice have identified areas where IT could be added to the existing activities of the general practice (e.g., links to digital medical libraries). However, although most GP practices in the UK are computerized, nurses tend to have little access to the system, especially for uses other than updating patient records (Miller and Jeffcote, 1997).

Changes in work practices can also be hindered by technological and human factors. In some cases, the technology in place (e.g., electronic mail and connection to the World Wide Web or WWW) may not work efficiently, or the systems used may not fit the general practice's wider needs and requirements (Shepherd, 1999). Furthermore, national and institutional guidelines for technological changes can be difficult to implement because health-care professionals, including nurses, cannot always grasp the benefits and potential of IT. For example, there is some evidence that when nurses in primary care are not involved in the introduction of IT into the workplace, they will miss the opportunity to enhance their practice and status (Miller and Jeffcote, 1997).
Changes in work practices also mean that healthcare professionals, including nurses, are faced with new challenges of communication and collaboration (Alpay and Heathfield, 1997). However, health-care professionals may be reluctant to alter their current modes of communicating and collaborating with colleagues - for example, in using electronic patient records in the practice (e.g., Swanson et al., 1999). In addition, as Herbert (1998) has pointed out, socio-economic and organizational factors impact on collaboration and communication. More and more health-care institutions (such as primary care centres) need to contain their expenditure, and aim to achieve increased quality of care and staff development while at the same time minimizing costs. Thus members of the primary care group must collaborate in order to maximize resources (e.g., Lock, 1995; Whitecross, 1999).

The introduction of information technology in the workplace impacts not only on changes in work practices but also on other related aspects such as changes in roles and responsibilities, and changes in 'culture'. For example, the roles and responsibilities of health-care professionals, including nurses, have been reported to change in relation to electronic access to and data entry of patient information (Herbert, 1998).

It is recognized that a culture change in nursing is taking place, and information technology is viewed by some nurses and nurse leaders as supporting rather than conflicting with activities (Procter, 1998). However, such a change would seem difficult to achieve in the short term when computer resistance and computer anxiety still affect a large number of nurses (Negron, 1995).

Are the changes in work practices brought about by IT always beneficial and desirable? This question merits consideration for, as Herbert (1998) points out, technological changes do not always result in better work practices. The need to spend more time using computers, and the necessary training for this, may result (at least temporarily) in less frequent interactions with patients.

\section{Training needs and requirements in information technology}

In this section, two separate educational contexts are discussed, namely training professional nurses in IT (as part of their continuing professional 
development) and integrating IT within the nursing curriculum.

\section{Information technology training for professional nurses}

It has been recognized for some time that healthcare professionals, including nurses, have an inadequate knowledge of the principles of health informatics (Hasman, 1994; Barnett, 1995). One of the main problems is that there is still little empirical research reported in the literature which has assessed the current situation of IT training needs and requirements for nurses (see, for example, in Wright, 1994; Murray, 1996; Simpson and Kenrick, 1997). Examples of studies investigating IT training for general practice have usually focused on GPs rather than on other members of the primary care team, such as nurses (e.g., Ahmed and Berlin, 1997).

Unfortunately, computer training for nurses is often either nonexistent or inadequate and targeted at audiences other than nurses, as was found for example for $80 \%$ of practice nurses interviewed in the study by Miller and Jeffcote (1997). It is also important to point out that GPs may not always give a high priority to the professional development of their colleagues, including nurses. Furthermore, in the UK the absence of any agreed accredited IT training for nurses, which has been highlighted in recent surveys (e.g., Miller and Jeffcote, 1997), has certainly contributed to the low level of IT literacy within this health-care group.

Where IT training programmes do exist, nurses are not always provided with IT educators who can appreciate their educational and learning needs. Thus these instructors often fail to facilitate the teaching-learning process without provoking anxiety and discomfort (Negron, 1995; Nagelkerk et al., 1998).

Other problems associated with IT training arise from the nurses themselves, in that they may lack interest and concerns in IT and may not have aspirations to develop their expertise in this area. Nurses in need of training in IT will have received their formal education before this technology was integrated into the curriculum, and some of them will not been been inclined to find out about developing computer technologies (Roberts and Peel, 1997). Furthermore, for some, training in IT is only seen as relevant when the information content is deemed to be directly helpful (e.g., if it is linked with training in the use of specific information management systems).

In addition, some nurses experience difficulties in prioritizing their learning needs due to the magnitude of these needs, including computerization and information technology (Lindner, 1998). Moreover, some nurses are being increasingly challenged by new educational demands. Continuing education through open and distance learning is an attractive way to acquire informatics skills. However, recent courses for newcomers to computers (e.g., some of the courses developed at the Open University in the UK) expect their learners to be able to adapt to novel study modes of communication and collaboration.

\section{Information technology within the nursing curricula}

There are various problems associated with nursing curricula. First, the number of nursing curricula which include informatics is limited (Mantas, 1998). This situation results in utilizing existing materials developed for health or medical informatics courses, or using materials from outside the health-care sector. Neither approach is desirable for nursing education. A related difficulty in nursing education is the fragmentation of the curriculum. That is, IT teaching modules are not always developed as an integral part of the curriculum itself (Carlile and Sefton, 1998).

The curriculum content for teaching IT to nurses is still far from achieving its goal (Travis et al., 1992). Although nurses are trained in the use of information technology, there are still areas of study that require attention. Frequently practical skills are limited (e.g., to word-processing software), and nurses lack knowledge of health information systems (Saranto, 1998). Furthermore, not enough emphasis is placed on support for nursing practice and nursing research (Moritz, 1990), and on bridging theory and practice in the use of IT (Crudele et al., 1996).

The learning environment in which nursing students acquire their knowledge and skills is also a crucial factor. One recent study showed that nursing students were dissatisfied with the current learning environment, and that they wanted more depth and breadth to the teaching of information technology (Saranto et al., 1997). The importance of learning in a peaceful environment when studying IT in nursing education has been stressed 
previously (Vanderbeek et al., 1994). Nurses need to be away from work pressure and delivery of nursing care. Thus an inadequate learning environment will not reduce initial computer anxiety and enhance computer literacy.

Another set of difficulties in incorporating IT in nursing curricula arises from the teachers themselves. The selection of those who teach nursing students is important and needs to be done carefully. For example, in a study by Saranto et al. (1997) it was found that nursing students felt that the best choice for a nursing informatics teacher was an IT teacher, rather than a nursing teacher. While some nursing academics feel comfortable teaching nursing students in informatics, others display negative attitudes towards computerization and thus hinder the implementation of technological advances in their academic settings (Lewis, 1997). Furthermore, with the advent of computer and telematics technologies, nursing educators need to rethink nursing education altogether. However, the need to re-examine and re-conceptualize the field of nursing in the light of IT still remains a problem for some (Ronald, 1991). Many of the issues discussed above were identified and discussed by Nelson (1997) in the early 1990s, but there is little evidence of substantial progress towards addressing them.

\section{Discussion}

The above section examined three types of difficulty documented in the recent literature on access to and use of IT by nurses. These aspects are closely intertwined. For example, negative attitudes towards computerization arise from a lack of training and positive experiences of exposure to IT. The changes in work practices that are brought about by computers and IT generally may initially be a source of anxiety about and resistance towards computers. The following section illustrates how these difficulties can be addressed, and discusses the emerging trends.

\section{Nurses' pro-activity}

Nurses need to work within a computer environment that can deal with the complexities of the care that they plan and deliver, rather than working with computer technologies that require them to adapt their practices to the computer environment. One way to achieve this is for nurses to be more proactive in finding out how IT coupled with adequate information management will improve their practice (Glen, 1998; Marin et al., 1998). The view that nurses ought to be involved in the IT revolution is also echoed by Negron (1995) and Keen and Malby (1992). It is through models like that proposed by Nagelkerk et al. (1998) that nurses can prepare themselves for computerization and change their negative attitudes. Those authors identified six factors that will successfully help nurses in nursing informatics, including strong leadership, effective communication and organized training sessions.

Furthermore, in order to be more pro-active nurses need to be reflective. For example, they should assess and aim to raise their levels of concern in their use of and access to IT. Stages of concern as proposed by Hall and Hord (1987) range from no concern or awareness, through interest and information-seeking to personal concern about how the computer innovation will affect the individual. These levels of concern can be applied to the nursing context (Barnett, 1995). For example, a nurse may have reached the personal level of concern about the technical aspect (e.g., being uncertain about the personal demands and her competence in using the technology) and at the same time be at a different level for the policy aspect (e.g., having only a general interest in the new NHS information strategy).

\section{Capitalizing on 'nursing intelligence'}

As work practices in primary care change, the role and responsibility of its nurses also change. Consideration is now given to 'nursing intelligence' (i.e., information gathered from nurses in their nursing work) and the nurse's role in utilizing such intelligence (Ballard, 1997). This view reinforces the idea of knowledge transfer as an evolving paradigm that will provide full and effective use of the technology by nurses (Ball et al., 1997). Furthermore, it is through methods such as focus groups that nurses can capitalize on nursing intelligence, explore their role in depth, and identify their information needs and requirements (Torn and McNichol, 1998). Strong leadership coupled with the capitalization of nursing intelligence will put nurses in a favourable position to lead IT innovations in their practices. 


\section{Assessing the use of information technology by nurses through a socio-technical perspective}

The introduction of IT in primary care means that nurses not only have to rethink and change their perceptions about computerization and IT, but they also have to adapt to new working practices. In order to have a better understanding of the impact of IT in primary care, especially for nurses, the nature of those changes needs to be assessed. This can be achieved by adopting a socio-technical approach. Indeed, there is an increased awareness of the interactive relationships between users such as nurses and the technology, and there is an increasing recognition of social, organizational, political and nontechnical factors surrounding IT use and access (Kaplan, 1997; Herbert, 1998).

Although the social interactionist perspective proposed by Kaplan (1997) still remains largely at a research level, this approach provides a useful framework for examining the impact of IT for nurses in primary care. This framework allows us to reflect on and raise questions about issues of communication, care, control and context that occur in primary care. For example, one may ask whether communication within the primary care team, as well as between the primary care team and the primary care group improve, and whether the delivery and quality of care is better. It is also important to identify who owns the electronic patient record and who controls the updates of the patient database.

\section{Need for empirical investigation}

In order to help nurses to change and improve their attitudes towards computers and IT, it is necessary to have details of the nurses' current situation in this area. It is important to investigate not only nurses' IT skills but also their understanding of information management using those skills. However, as stated in the previous section, there is little empirical evidence in the literature. It is acknowledged that more empirical investigation is needed to assess the situation (e.g., Negron, 1995; Strachan, 1996; Marin et al., 1998). At the Open University in the UK, the work in progress in the project PRACTIS (PRimary care nurses Access to Communications Technology and Informatics Skills), led by the first author of this paper, aims to collect empirical evidence on the current levels of access to and use of IT by practice nurses in Buckinghamshire, UK. The project also aims to assess nurses' educational needs and to investigate their perceptions of the proposed benefits of IT to their practice and lifelong professional development.

\section{Adequate nursing training programmes}

Changes, either of attitudes or of work practices, brought about by the introduction of IT into primary care need to be complemented by comprehensive IT training programmes (Lynn, 1995; Fullerton and Graveley, 1998). Although courses in information technology that are offered to healthcare professionals are usually satisfactory for teaching the use of specific software packages, they fail to provide a broader overview of the potential of IT (Saranto, 1998). Nurses need support as they develop their understanding of the benefits of IT for patient care, and of the complexity of using information technology. More attention is now given to metacognition and cognitive tools to facilitate higher-order thinking skills required for the effective use of IT in nursing education (e.g., Ribbons, 1998). Furthermore, educating nurses in IT ought to act as a bridge between the learning needs of the nurses and the needs of the care setting (Lindner, 1998). For example, understanding the fundamentals of IT can help nurses to apply evidence-based nursing by accessing computerized databases (Kessenich et al., 1997).

The situation with regard to IT training for nurses is now slowly evolving (Barnett, 1995; Nagelkerk et al., 1998). In the UK, a number of initiatives have supported nurses in identifying their own training and development needs, such as the NHS Enabling People programme (NHSTD, 1995). Furthermore, the new NHS Information Strategy, Information for Health (Department of Health, 1998), has set out specific objectives to address these issues for nurses. At an international level, recent recommendations on education in health and medical informatics, including information technology, have been put forward by the working group of the International Medical Informatics Association (IMIA) (IMIA Working Group 1, 1999). In the USA, an informatics agenda for nursing education has been put in place to prepare nurses to develop and use IT (Gassert and Salmon, 1998).

Successful IT training for nurses requires not only that the subject matter be prepared adequately 
to meet nurses' learning needs but also that IT be taught by carefully selected educators. There is a need for a more humanistic approach to teaching informatics in nursing continuing education (Negron, 1995).

A further issue associated with IT training that is worth pointing out here centres around information contents. There is a growing view that, in order to be of practical value for nurses, IT training ought to be complemented by adequate training in information management (e.g., English National Board for Nursing, Midwifery and Health Visiting, 1998).

\section{Conclusions}

It is clear that the future development of health care will be increasingly underpinned by sophisticated use of information technology. Nurses in primary care are faced with the challenge of making IT a valuable tool in their practice. Drawing from current literature, this paper has as its focus some aspects which hinder successful access to and use of IT by nurses in primary care, namely attitudes towards computerization and IT, changes in work practices, and education and training needs in IT. Although solutions to these difficulties are under way, there are still discrepancies between the reality of today and the ultimate vision of the 'ITskilled' nurse. It is by actively addressing these challenges, recognizing the benefits of IT coupled with adequate information management, and by taking charge of their future that nurses in primary care will be equipped to meet the technological advances of the twenty-first century with confidence.

\section{Acknowledgements}

The authors would like to thank Paula Procter from CTI Centre for Nursing and Midwifery, University of Sheffield, and Anita Reed from Buckinghamshire Health Authority for comments on the manuscript.

\section{References}

Ahmed, A. and Berlin, A. 1997: Information technology in general practice: current use and view on future development. Journal of Informatics in Primary Care November, 5-8.
Alpay, L. and Heathfield, H. 1997: A review of telematics in health care: evolution, challenges and caveats. Health Informatics Journal 3, 81-92.

Ball, M., Douglas, J. and Hoehn, B. 1997: New challenges for nursing informatics. In Gerdin, U., Talberg, M. and Wainwright, P., editors. Nursing informatics - the impact of nursing knowledge on health care informatics. Amsterdam: IOS Press, 39-43.

Ballard, E. 1997: Important considerations about nursing intelligence and information systems. In Gerdin, U., Talberg, M. and Wainwright, P., editors, Nursing informatics - the impact of nursing knowledge on health care informatics. Amsterdam: IOS Press.

Barnett, D. 1995: Informing the nursing professions with IT. In Greenes, R., Peterson, H. and Protti, D., editors. Proceedings of the Eighth World Congress on Medical Informatics (MEDINFO '95), Vancouver. Edmonton, Alberta: Healthcare Computing and Communications Canada Inc., 1316-20.

Brown, J. 1998: The computer in the general practice consultation: a literature review. Health Informatics Journal 4, 106-8.

Carlile, S. and Sefton, A. 1998: Healthcare and the information age: implications for medical education. Medical Journal of Australia 168, 340-43.

Crudele, M., Binetti, P., Serio, A. and Tartaglini, D. 1996: The teaching of informatics to first-year students of medicine and nursing, through an interdisciplinary innovative methodology. In Brender, J., Christensen, J., Scherrer, J.-R. and McNair, P., editors. Proceedings of Medical Informatics Europe (MIE '96). Amsterdam: IOS Press, 823-27.

Department of Health 1997: The new NHS: modern, dependable. London: The Stationery Office.

Department of Health 1998a: Information for health - an information strategy for the modern NHS 1998-2005. Wetherby: NHS Executive.

Department of Health 1998b: A first class service: quality in the NHS. London: The Stationery Office.

English National Board for Nursing, Midwifery and Health Visiting (ENB) 1998: Information for caring. London: ENB.

Fogarty, L. 1997: Primary care informatics development: one view through the miasma. Journal of Informatics in Primary Care January, 2-11.

Fullerton, J. and Graveley, E. 1998: Enhancement of basic computer skills - evaluation of an intervention. Computers in Nursing 16, 91-94.

Gassert, C. and Salmon, M. 1998: Setting a national informatics agenda for nursing education and practice to prepare nurses to develop and use information technology. In Cesnik, B., McCray, A.-T. and Scherrer, J.-R., editors. Proceedings of the Ninth World Congress on Medical Informatics (MEDINFO '98), Seoul, Korea. Amsterdam: IOS Press, 748-51.

Glen, S. 1998: The tension between 'IT' and 'values thinking': implications for health and social care education. Proceedings of the Second National Conference of the CTI Centre for Nursing and Midwifery, 'Communications across professional boundaries - can technology help?'. Sheffield: CTINM Publications, 39-50. 
Hall, L. 1996: Health informatics in general practice. In Hovenga, E., Kidd, M. and Cesnik, B., editors. Health informatics: an overview. Melbourne: Churchill Livingstone, 303-12.

Hall, G. and Hord, S. 1987: Change in schools: facilitating the process. New York: State University of New York Press.

Hasman, A. 1994: Education and training in health informatics. Computer Methods and Programs in Biomedicine 45, 41-43.

Herbert, M. 1998: Impact of IT on health care professionals: changes in work and the productivity paradox. Health Services Management Research 11, 69-79.

IMIA Working Group 1 1999: Recommendations of the International Medical Informatics Association (IMIA) on Education in Health and Medical Informatics. Report of IMIA Working Group 1. Göttingen: International Medical Informatics Association.

Kaplan, B. 1997: Addressing organisational issues in the evaluation of medical systems. Journal of the American Medical Informatics Society 4, 94-101.

Keen, J. and Malby, R. 1992: Nursing power and practice in the United Kingdom National Health Service. Journal of Advanced Nursing 17, 863-70.

Kessenich, C., Guyatt, G. and DiCenso, A. 1997: Teaching nursing students evidence-based nursing. Nurse Education 22, $25-29$.

Lacey, D. 1993: Nurses' attitudes towards computerisation: a review of the literature. Journal of Nursing Management 1, 239-43.

Lewis, D. 1997: Implementing instructional technology - strategies for success. Computers in Nursing 15, 187-90.

Lindner, R. 1998: A framework to identify learning needs for continuing nurse education using information technology. Journal of Advanced Nursing 27, 1017-20.

Lock, K. 1995: Primary health care: using computers to enhance care in a GP practice. Nursing Times 91, 36-38.

Lynn, Z. 1995: Change and technology in nursing education. In Greenes, R., Peterson, H., Protti, D. et al., editors. Proceedings of the World Congress on Medical Informatics (MEDINFO '95). Amsterdam: Elsevier Science Publishers, 1357-61.

Mantas, J. 1998: Advances in health telematics education - a Nightingale perspective. Studies in Health Technology and Informatics. Volume 51. Amsterdam: IOS Press.

Marin, H., Cunha, I. and Safran, C. 1998: Nurses' requirements for information technology in the next millennium. In Cesnik, B., McCray, A.T. and Scherrer, J.-R., editors. Proceedings of the Ninth World Congress on Medical Informatics (MEDINFO '98), Seoul, Korea. Amsterdam: IOS Press, 1314-17.

Miller, A. and Jeffcote, R. 1997: Practice nurses and computing: some evidence on utilization, training and attitudes to computer use. Health Informatics Journal 3, 10-16.

Moritz, P. 1990: Information technology - a priority for nursing research. Computers in Nursing 8, 111-15.

Murray, P. 1996: Research and the Internet: some practical and ethical issues. Nursing Online 10, http://www.nursingstandard.co.uk/week28/ol-art.htm

Nagelkerk, L., Ritola, P. and Vandort, P. 1998: Nursing

Primary Health Care Research and Development 2000; 1: 5-13 informatics: the trend of the future. Journal of Continuing Education in Nursing 29, 17-21.

Negron, J. 1995: The impact of computer anxiety and computer resistance on the use of computer technology by nurses. Journal of Nursing Staff Development 11, 172-75.

Nelson, R. 1997: Nursing informatics education and opportunities disguised as problems. In Barnett, D., editor, Sharing information: key issues for the nursing professions. Volume 1. INFOrmed Touch Series. Swindon: The British Computer Society, 88-92.

NHSTD 1995: Education and training programme in IM\&T for clinicians: a framework for nurses. Volume 5. Bristol: NHSTD.

Procter, P. 1998: Responses within the virtual conference. Action One: culture change. Proceedings of the Second National Conference of the CTI Centre for Nursing and Midwifery, 'Communications across professional boundaries - can technology help?', University of Sheffield. Sheffield: CTINM Publications.

Ribbons, R. 1998: The use of computers as cognitive tools to facilitate higher-order thinking skills in nurse education. Computers in Nursing 16, 223-28.

Roberts, J. and Peel, V. 1997: Getting IT into shape - external factors affecting the potential benefits from health informatics. In Pappas, C. et al., editors. Proceedings of Medical Informatics Europe (MIE '97). Amsterdam: IOS Press, 825-28.

Ronald, J. 1991: The computer as a partner in nursing practice: implications for curriculum change. Lecture Notes in Medical Informatics 46, 149-53.

Saranto, K. 1998: Outcomes of education in information technology at nursing polytechnics. Health Informatics Journal 4, 84-91.

Saranto, K., Leino-Kilpi, H. and Isoaho, H. 1997: Learning environments in information technology - the view of student nurses. Computers in Nursing 15, 324-32.

Scarpa, R., Smeltzer, S. and Jasion, B. 1992: Attitudes of nurses towards computerization: a replication. Computers in Nursing $10,72-79$.

Shepherd, S. 1999: Primary care groups are a catalyst for change. Windows on Healthcare 5, 20-22.

Simpson, G. and Kenrick, M. 1997: Nurses' attitudes towards computerisation in clinical practice in a British general hospital. Computers in Nursing 15, 37-42.

Simpson, L., Nestor, G., Bojke, C. and Purves, I. 1998: Gender issues in primary care computing. Proceedings of the Primary Health Care Specialist Group Annual Conference, Cambridge.

Strachan, H. 1996: Nursing informatics: a Delphi study. In Brender, J., Christensen, J., Scherrer, J.-R. and McNair, P., editors, Proceedings of Medical Informatics Europe (MIE '96). Amsterdam: IOS Press, 867-71.

Swanson, T., Dostal, J., Eichhorst, B., Jernigan, C., Knox, M. and Roper, K. 1999: Recent implementations of electronic medical records in four family practice residency programs. In van Bemmel, J. and McCray, A., editors. Yearbook of medical informatics. Rotterdam: Schattauer, 377-82.

Torn, A. and McNichol, E. 1998: A qualitative study-utilizing group to explore the role and concept of the nurse practitioner. Journal of Advanced Nursing 27, 1202-11. 
Travis, L., Hoehn, B., Root, A. and Youngblut, J. 1992: In Lun, K. et al., editors. Proceedings of the World Congress on Medical Informatics (MEDINFO '92). Amsterdam: Elsevier Science Publishers, 998-1003.

Vanderbeek, J., Ulrich, D. and Jaworski, R. 1994: Bringing nursing informatics into the undergraduate classroom. Computers in Nursing 12, 227-31.
Whitecross L. 1999: Collaboration between GPs and nurse practitioners: the overseas experience and lessons for Australia. Australian Family Physician 28, 349-53.

Wright, G. 1994: A review of current IM\&T provision within preand post-registration nurse training. Manchester: Health Services Management Unit Centre for Health Informatics, University of Manchester. 